This item was submitted to Loughborough's Research Repository by the author.

Items in Figshare are protected by copyright, with all rights reserved, unless otherwise indicated.

\title{
Failed summons: Phonetic features of persistence and intensification in crisis negotiation
}

\section{PLEASE CITE THE PUBLISHED VERSION}

https://doi.org/10.1016/j.pragma.2019.01.023

\section{PUBLISHER}

(C) Elsevier

VERSION

AM (Accepted Manuscript)

\section{PUBLISHER STATEMENT}

This work is made available according to the conditions of the Creative Commons Attribution-NonCommercialNoDerivatives 4.0 International (CC BY-NC-ND 4.0) licence. Full details of this licence are available at: https://creativecommons.org/licenses/by-nc-nd/4.0/

\section{LICENCE}

CC BY-NC-ND 4.0

\section{REPOSITORY RECORD}

Sikveland, Rein. 2019. "Failed Summons: Phonetic Features of Persistence and Intensification in Crisis Negotiation". figshare. https://hdl.handle.net/2134/36732. 


\title{
Failed summons: Phonetic features of persistence and intensification in crisis negotiation
}

\begin{abstract}
This paper explores crisis negotiators' practices for summoning persons in crisis who are unavailable, unable or unwilling to respond. A corpus of audio recorded interactions between a UK police hostage and crisis negotiation unit and (suicidal) people in crisis was analysed. The analysis shows how low to moderate phonetic upgrades in pitch, and small variations in loudness, duration and articulatory setting are associated with interactionally 're-doing' a subsequent summons. In contrast, marked phonetic upgrades in pitch, loudness and articulatory setting are associated with an increase in danger or concern. And whereas phonetic upgrading of a self-repeated summons is found in cases where the recipient is unavailable, unable or unwilling to respond, phonetic downgrading treats the silence as responsiveness in progress, where the summons repetition does extra work to further secure the person's joint attention to a projected new course of action. I discuss the complexities of applying an 'upgrade-downgrade' continuum to account for repeated action and consider the wider implications of phonetic design on crisis management.
\end{abstract}

\section{Introduction}

One method with which speakers can operate on past turns of talk is through 'upgrading' or 'downgrading' its lexical and phonetic features in a next turn of talk. In conversation analytic research, descriptions of upgrading and downgrading have been applied to the analysis of, for example, agreement/disagreement (e.g., Heritage and Raymond, 2005; Ogden, 2006; Pomerantz, 1984a; Sorjonen and Hakulinen, 2009), repair sequences (Curl, 2005), and dealing with absent responses (Bolden et al., 2012). This paper focusses on the phonetics of 'upgrading-downgrading' in repeated (i.e., failed) attempts to summon its recipient.

The study is based on recorded encounters between professional crisis negotiators and persons in crisis. In this study, a person in crisis (henceforth, $\mathrm{PiC}$ ) refers to someone who is threatening to commit suicide, or otherwise harm themselves, and police negotiators are present to halt or reverse this process. In the data, PiCs are located at some distance from the negotiators, situated on top of a roof, or barricaded in a flat, while the negotiators are on the ground or somewhere near the building, speaking to PiC across the physical distance, or on the telephone.

The objective is to identify how negotiators maintain their effort to summon, i.e. establish joint participation with, $\mathrm{PiC}$, when they remain unresponsive. By repeatedly calling for PiC's joint participation, a negotiator may orient to an increase (or decrease) in danger or concern. Based on a conversation analytic approach, I focus on whether the phonetic variability of the self-repeated summons can be accounted for in terms of these variable 
orientations to a crisis, and to what extent these fit within the dichotomy 'upgrading' and 'downgrading'.

Following an introduction to previous accounts of repeated summoning (Section 1.1), of repetition and the phonetics of upgrading and downgrading in interaction (Section 1.2), I provide further details on how self-repeated summoning and phonetic upgrading/downgrading was defined for this study in Data and Methods (Section 2). The Analysis is presented in Sections 3.1-2, followed by a Discussion and Conclusion in Sections 4 and 5.

\subsection{When a summons is not responded to}

Summoning a speaker is a dedicated interactional resource available for securing a joint agreement between two or more parties to start a conversation or a sequence of talk (Schegloff, 1968). The summoning may fail to get a response, however, for example in settings where a speaker is dealing with many recipients, such as classrooms (Cekaite, 2008; Gardner, 2015), or large social gatherings (Good and Beach, 2005). In a classroom, students may summon the teacher while they are engaged with another student and may withhold answering the summons to maintain shared attentiveness in another, concurrent conversation (Gardner, 2015). Thus, a failed summons can be a matter of unavailability; but also, even when a recipient is physically present and within audible range, a recipient may be unable or unwilling to respond. Summoning may fail in different situations and contexts. For example, a recipient's inability to respond may be ascribed a medical or psychiatric condition (Bergman, 2016), or their developmental stage (Walker, 2017), and a child might also choose to ignore the summons to resist a projected directive or admonishment from their parent (Kidwell, 2013). In this paper the data presents us with failed summonses in crisis situations, where PiC's unresponsiveness gets oriented to as at least one of the three accounts: 1) a person in crisis may be unavailable if moving away from visible or audible range, 2) they may display unwillingness in order to disengage with the conversation and the negotiation progress, 3 ) they may be unable to respond due to medication, drugs, or self-harm. Any of these accounts may be associated with danger and concern.

While previous research has shown different circumstances in which summonses may be repeated, and the implications for sequential development (e.g. Gardner, 2015; Kidwell, 2013), there has been little attention to the phonetics of summonses (see Voilmi and Wiklund, 2013 for a prosodic study of names in multi-party interaction) and particularly self-repeated summonses. Kidwell (2013) attends to some instances of repeated summonses where there are 'volume shifts', as well as 'sound stresses' and 'sound stretches', before turning to other resources which more strongly call on the child to change their behaviour; however, unlike the present paper the proposed phonetic features are not the focus of Kidwell's study.

Extract 1 presents a preliminary example, in which a negotiator (henceforth, $\mathrm{N}$ ) attempts to re-establish a conversation with a PiC anonymised as "Mosi". Prior to this 
encounter, PiC prematurely ended a mobile phone conversation with the negotiators, and $\mathrm{N}$ is now addressing $\mathrm{PiC}$ from the ground below the building on which $\mathrm{PiC}$ is positioned.

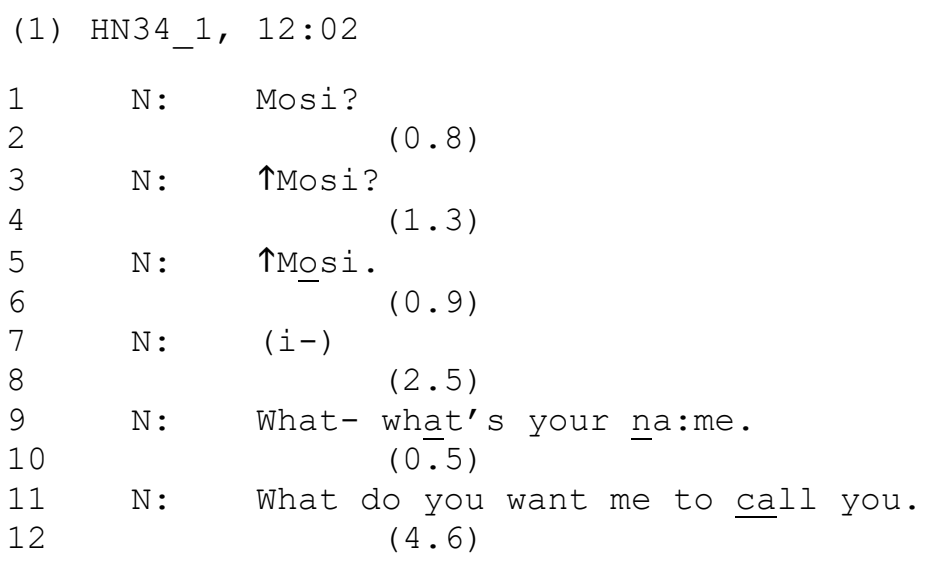

N's production of the address term "Mosi?" in line 1 acts as a summons making an answer relevant next to establish joint participation (Schegloff, 1968). N makes two additional attempts at summoning $\mathrm{PiC}$ in lines 3 and 5 . Following the third failed summons, $\mathrm{N}$ persists pursuing a response with two WH-questions in lines 9 and 11 . That is, having failed to establish PiC's joint participation more than once, N now seeks to remedy PiC's unresponsiveness with alternative means. Such problem-solving has previously been associated with post-silence treatment in pursuits of other actions such as invitations, offers, and proposals (Davidson, 1984). Here, the proposed solution (lines 9 and 11) is to establish the appropriate address term, suggesting that PiC's real name might not be "Mosi", and/or that PiC might prefer a different address term. Other research has found that it is common for people in crisis not to provide their names (Lester and Brockopp, 1973). This supports Sacks' (1992) finding in suicide helpline calls, that callers systematically avoid giving their real names. N's first interrogative, "what's your na:me." (line 9), which on its own indicates uncertain knowledge, is followed by "what do you want me to call you." (line 11), which points directly to naming as an issue to do with PiC's preference, regardless of what is his real name. In doing so, $\mathrm{N}$ treats $\mathrm{PiC}^{\prime}$ 's unresponsiveness as unwillingness (due to address term) rather than PiC's basic ability to hear or understand the summoning action put forward.

The three summonses (lines 1-5) show some phonetic variability, some of which represent a phonetic 'upgrading': The second summons (line 3) has slightly higher pitch maximum and overall loudness than the first summons, and the third summons (line 5) has slightly higher pitch maximum than the second summons ${ }^{1}$; also, line 5 has a rise-fall pitch contour compared to a fall-rise contour in lines 1 and 3. But although the increased pitch and loudness features may be phonetically upgraded in each of these summonses, there is

\footnotetext{
${ }^{1}$ The pitch, loudness and duration features are to some extent represented in the transcript, following Jefferson's (2004) conventions. The pitch difference between the summonses in lines 3 and 5 is not sufficient to be marked with an additional upward arrow.
} 
no interactionally evident change in N's orientation to danger or concern, for example, and $\mathrm{PiC}$ remains unresponsive. The observable orientations to the summonses will be central to the categorisations in this study (see Section 2).

\subsection{Repetition and the phonetics of upgrading and downgrading}

One of the most systematic and detailed investigations into the interactional relevance of phonetic (and lexical) downgrading/upgrading is found in Ogden (2006). Building on Pomerantz' (1984) classic study of agreements to assessments, Ogden (2006) demonstrated how second position assessment turns differ in terms of phonetic features, and how these features mark agreement vs. prefacing disagreement with first position assessment turns. The group of phonetic features (categorised as upgrades) which generally marked agreement, were associated with tighter articulations, wider pitch span, and slower articulation rate. In contrast, the other group of phonetic features (i.e., downgrades), generally treated as prefacing disagreement, were associated with open articulations, narrower pitch span, faster articulation rate. Ogden (2006) also showed that, while there is variation in the association between phonetics and agreement, the prior talk provides a phonetic context for upgrading or downgrading a prior turn. In this way upgrading stands in opposition to downgrading, and there is a socially meaningful distinction between the two.

Like 'upgrading-downgrading', 'repetition' is subject to a wide range of uses and descriptions in conversation analytic research (e.g. Curl et al., 2006; Local, Auer and Drew, 2010; Schegloff 2004), including some studies of the phonetics of repetition (e.g. Curl et al., 2006; Local et al., 2010). The advantage of studying the phonetics of repetition is that the repetition and the repeated unit are relatively similar lexically and syntactically, therefore reducing the number of variable domains. Curl's $(2002 ; 2005)$ pioneering work on the phonetics of other-initiated repairs (initiated by "huh?", "pardon?") showed how their phonetic variability is systematically tied to the sequence in which they occur. Curl identified two groups of phonetic patterns of repairs, one with expanded pitch ranges, longer durations, and long-domain changes in articulation relative to the trouble-source turn. In the other group, the repairs were not louder, not longer, and had non-expanded pitch ranges compared to the trouble-source. It was shown that the choice of these two patterns, phonetic 'upgrade' and 'downgrade' respectively, corresponded to the interactional difference between trouble source turns that are fitted (upgrade) and disjunctive (downgrade) relative to the ongoing talk (Curl, 2005). This study shows how phonetic features shape repair, based on the wider sequential environment in which they occur. And in a wider sense, it shows how participants themselves mark continuity and disjunction within and across turns of talk (see also Ogden, 2012).

The phonetics of repetition has also been studied in the context of making a second attempt at a turn which had been abandoned, often due to simultaneous, or 'interjecting', talk by a co-participant (Local, 1992; Local et al., 2010). The abandoned turn may then be repeated by its producer, at the earliest opportunity, or when they have responded to the 
co-participant's interjection, and/or when the current topic has come to a close (Local et al., 2010). Local et al. identified phonetic characteristics which differed according to sequential context: repetitions that occur at the first opportunity ('reiterations') were typically phonetically 'downgraded' (no greater pitch range, same or lower pitch maximum, same or reduced loudness) compared to the abandoned turn. On the other hand, repetitions that occurred following further attention to the on-going sequence of talk ('re-doings'), were associated with upgrading (higher pitch features, louder and longer duration). Thirdly, 'resuscitations', which occurred at a greater distance from the abandoned turn, did not reveal any particular phonetic characteristics. The authors argued that, while conversationalists normally produce a second attempt in a way which can be recognised as a second attempt ('reiterations' and 're-doings'), they might avoid any such association (some 'resuscitations'), thereby treating a repetition as a second first attempt.

By 'repeating' something, a speaker operates on the relevance of an already initiated action, which makes it noticeable as a 'repetition'. And participants are doing so for an interactional purpose, for example to remedy an absent response, i.e. identifying a reason for the absence and thereby treating the it as indicative of some problem (Bolden et al., 2012; Pomerantz, 1984b). On these grounds the notion of 'repetition' in interaction might be problematised; the sequential context is invariably not quite 'the same' on the subsequent production. Studying 'repetition' in situ (see Curl et al., 2006) enables us to account for the variation associated with treating something as a subsequent first, second or, in this paper, maintain or (de-)escalate an attempt at dealing with unresponsiveness.

Based on this background, this paper poses the following research question:

1) How is phonetic variability of self-repeated summonses tied to maintaining an effort to summon (i.e., establish joint participation with) a person who is unavailable, unable or unwilling to respond?

This research question is based on interactionally founded orientations to unresponsiveness, i.e., the methods with which participants display whether the summoning effort is maintained, or whether a repeated summons displays something more (or less) than that. The study aims to contribute with knowledge on the range of interactional phenomena associated with phonetic upgrading and downgrading, with implications for understanding some of the resources crisis negotiators have for remaining persistent and calm, and/or escalating a crisis situation when necessary.

\section{Data and Methods}

A UK police hostage and negotiation unit supplied audio recordings of interactions between people in crisis (PiCs) and negotiators (Ns), recorded at the scene as a routine part of their job. The data were provided as part of a larger conversation analytic study of crisis negotiation. The analysis presented is based on 14 individual cases (31 hours in total). All 
the cases presented in this paper ended successfully (no harm or death). The negotiations are usually led by one negotiator ('N1'), who is supported by a team of three other negotiators, one of whom ('N2') has the job of communicating with N1 while not disrupting the progress of N1's interaction with PiC. In a few instances, one of which shown below, more than one negotiator interacts with the $\mathrm{PiC}$ at a time. Interactions were either on the telephone or face-to-face (often at a distance; e.g., PiC is on a roof while N1 and N2 are on the ground). One important constraint in the negotiators' work is the risk involved in moving closer towards PiC. Negotiators might therefore be left summoning, or otherwise seeking a response, from the $\mathrm{PiC}$ for an extended time.

Address terms produced by $\mathrm{N}$ and directed at $\mathrm{PiC}$ to (re-)establish joint participation PiC were collected and analysed using a conversation analytic approach (Sidnell and Stivers, 2013). The collected address terms were all doing 'summoning', which, while it is rarely ambiguous who $\mathrm{N}$ addresses in this data, treat PiC's ability or willingness to engage as in doubt (see Lerner, 2003). The operational definition of a 'summons' includes free-standing address terms that a) operate prior to a focussed interaction (Schegloff, 1968), or b) within an ongoing interaction (Clayman, 2013). The operational definition initially also included turn-prefatory address terms, which, according to Clayman (2013), "also advance a claim on the recipient's attention and participation", and "although they do so embeddedly and in passing rather than as a separate and discrete action", display "quasi-summoning" properties (p. 292). However, the turn-prefatory address terms were excluded from the phonetic analysis to limit factors influencing phonetic variability. Also, to ensure that phonetic comparisons were made within single sequences of summonses, I treated clear shifts in the negotiator's attention to summoning PiC (e.g., talking to other negotiators) as the end of each summons sequence. Summons series separated by long gaps (found up to 11 seconds in the data) were otherwise included in the collection.

The study's objective is to demonstrate the relevance of maintaining, or (de)escalating, an effort to get a response using self-repeated summonses. The emerging categories are based on the members' own conduct, and the phonetic analyses formed the next analytic stage. The phonetic features explored were: pitch maximum, contour and range; loudness/intensity, duration, and articulatory setting. Impressionistic phonetic methods (see Local, 2003) were primarily used to evaluate articulatory setting and loudness, and for pitch, intensity and duration values acoustic measurement were made using speech software Praat (Boersma and Weenink, 2018). Throughout, references to phonetic 'upgrades' and 'downgrades' build in previous studies on the phonetics of talk-in-interaction (Curl, 2005; Local et al., 2010; Ogden, 2012; Plug, 2014).

Pitch variation is described with reference to semitones, which takes into account our nonlinear perception of frequency (Walker, 2017). The relationship between (perceptual) loudness and (physical) intensity is complex, with loudness influenced by perceived vocal effort as well as acoustic intensity (Allen, 1971). I rely primarily on impressionistic loudness in this study, and refer to intensity as part of that analysis. Articulatory setting was assessed based on the perceived tightness of consonants, and of 
vowel quality (see e.g. Ogden, 2006). As all names are anonymised in the transcripts, the analysis makes no reference to consonant or vowel categories, but instead with reference to how far or close they are to an optimised version of the relevant speech sound. The anonymised names in the transcripts have same number of syllables, syllable structures, and stress patterns as the original names.

The analysis is presented in three sections, focussing on 're-doing' summonses differ from 'escalating' summonses (Section 3.1), and finally, making a case for a different, 'attenuated', function of self-repeated summonses in Section 3.2.

\section{Analysis}

In the analysis I identified various efforts to persist summoning to deal with PiC's unresponsiveness. Three categories emerged. The first, and most commonly found type of self-repeated summons, demonstrates an effort to remedy unresponsiveness without markedly escalating or de-escalating the situation. I categorise these as 're-doing' summonses. In 're-doing' summonses relative pitch maximum is phonetically similar or upgraded, but not downgraded. The loudness is similar across the 're-doings' summonses, while there are small amounts of variation in duration (up to $0.1 \mathrm{~s}$ shorter/longer per syllable), and articulation (slight differences consonant tightness and vowel quality). However, pitch range and contour may vary more noticeably (e.g., narrow or expanded/final rise or fall).

In contrast to 're-doings', 'escalations', draw marked attention to the implications of the recipient's unresponsiveness: while escalations treat the recipient as within audible range, they orient to critical or concerning aspects of the unresponsiveness. Like 're-doings', 'escalations' are associated with phonetic upgrading, but with higher relative pitch maximum than 're-doings'. 'Escalations' are also associated with shorter, more peripheral and monophthongal vowel productions and tighter consonant productions than 're-doings', and with a sharper rise-fall pitch contour, and increased loudness. The analysis presented in Section 3.1 demonstrates these main findings, while Section 3.2 shows the only clear case of phonetic 'downgrading' of pitch maximum and loudness in the data: This case was identified at the boundary the current data collection, as it implies a sequential shift while also dealing with unresponsiveness. I argue for labelling this an 'attenuated' type of self-repeated summons (see Hauser, this issue).

\subsection{From 're-doing' to 'escalating' summonses}

In this section I demonstrate how 're-doing' and 'escalating' summonses emerge as categories relevant to how summoners themselves orient to their maintained or intensified effort in dealing with unresponsiveness. I show how particularly pitch maximum, loudness and articulatory setting is systematically associated with this distinction.

Extracts 2-3 present a series of summonses following one case of a PiC disengaging from the interaction with the negotiators (both N1 and N2 are engaging in a conversation 
with PiC in this case). PiC, who is anonymised as Karl, is situated on a rooftop while the negotiators are on the ground below him. Prior to, and in the beginning of Extract 3 , the Ns and $\mathrm{PiC}$ are engaged in a conversation from this distance. $\mathrm{PiC}$ has moved from engagement to disengagement whilst discussing with the negotiator the alcohol he has taken that evening. Just prior to line $1, \mathrm{PiC}$ moves away from visible reach of the negotiators, and Extract 2 starts when $\mathrm{N} 1$ summons $\mathrm{PiC}$ to return to a place of joint visibility and participation. Increasingly, the negotiators display concern (Extract 4), and eventually they decide to leave PiC alone for some time.

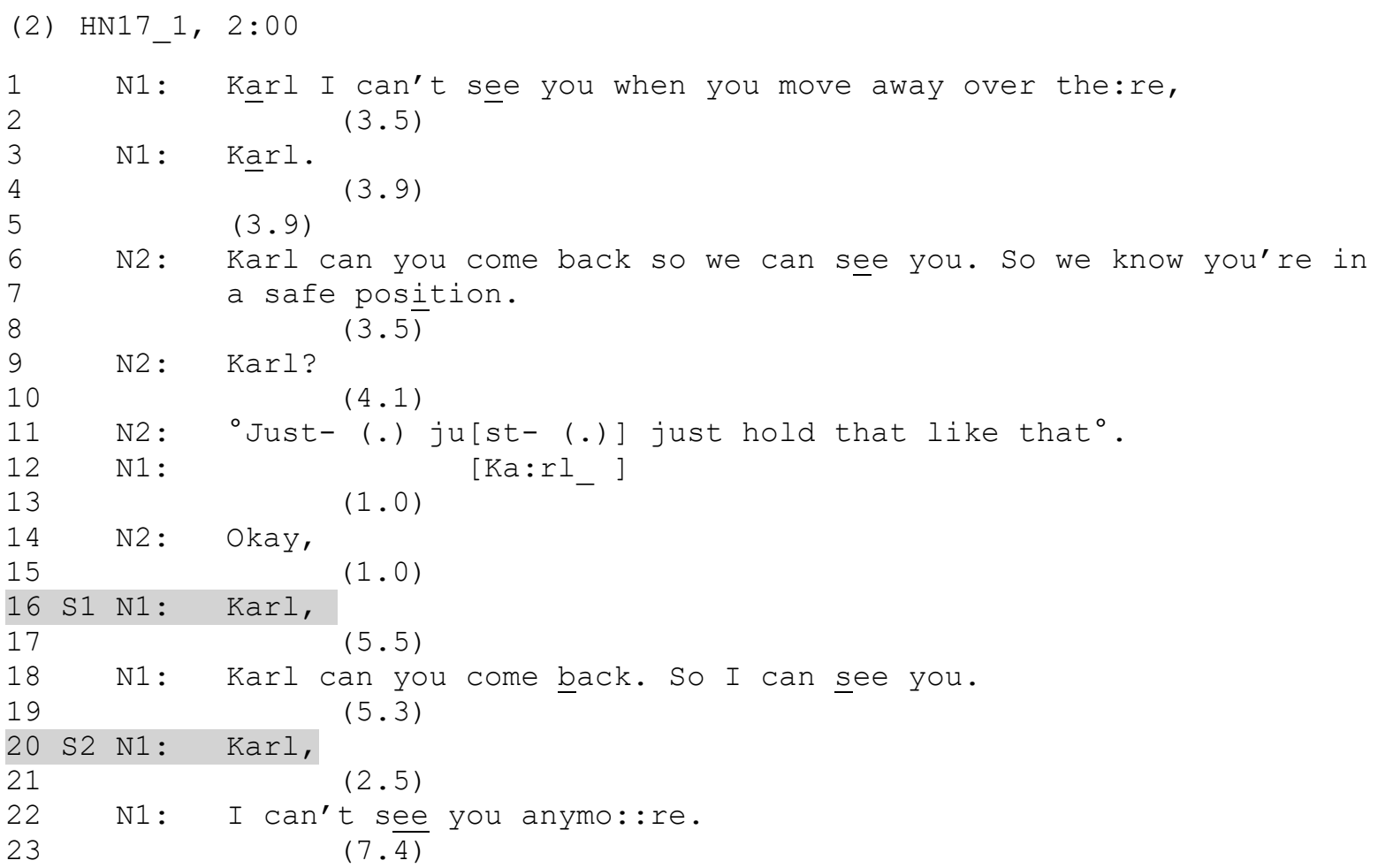

In line $1 \mathrm{~N} 1$ initiates a new first-pair part to deal with PiC's availability. Following no response (line 2), N1 summons PiC with a free-standing "Karl.". As there is no response still, $\mathrm{N} 2$ temporarily takes over summoning PiC (lines 6-9), and there is a brief interaction between N2 and N1 (lines 11-14) before N1 continues summoning PiC in lines 16-20. It is this series of summonses (marked as S1 and S2) that we focus one here (line 18 also contributes to the continued summoning, but was excluded from the phonetic analysis due to it being turn-prefatory; see Section 2). S1 is followed by a 5.5s gap. In line 18 the address term prefaces a request and an account which highlights the lacking visibility of $\mathrm{PiC}$ as an issue ("Karl can you come back. So I can see you."). Then, in line 20, following a 5.3s gap, N1 produces a second free-standing summons. Following another gap of 2.5s (line 22), and in further orientation to having failed to secure PiC's response, N1 complains about PiC's unavailability in line 22 ("I can't see you anymo::re.").

While N1 can be seen to complain about PiC's unresponsiveness, there is no interactionally evident change in N1's orientations to the unresponsiveness becoming more 
(or less) critical, for example in terms of increased (or decreased) danger or concern. This is the basis for labelling S2 as 're-doing' S1 here.

Phonetically, S2 has similar pitch maximum, within one semitone, compared to S1, and both have a slight fall-rise pitch contour. Neither summons is noticeably louder than the other; their durations are just below 0.5 seconds, and in terms of articulation, S1 and S2 are near identical, with a relatively lax consonant production and slightly diphthongised vowel quality. Figure 1 shows the pitch, duration and intensity features separately for the two subsequent summonses (S1 and S2 on the top row).

Immediately following Excerpt 2, N1 proceeds summoning PiC, still with no response. In Extract 3 we see that there is more phonetic variation between the summonses compared to S1 and S2, but that this variation is limited in terms of pitch peak and loudness. As in Extract 2, the subsequent summonses do not seem to warrant a change in displayed urgency or concern.

(3) HN17_1, 2:53

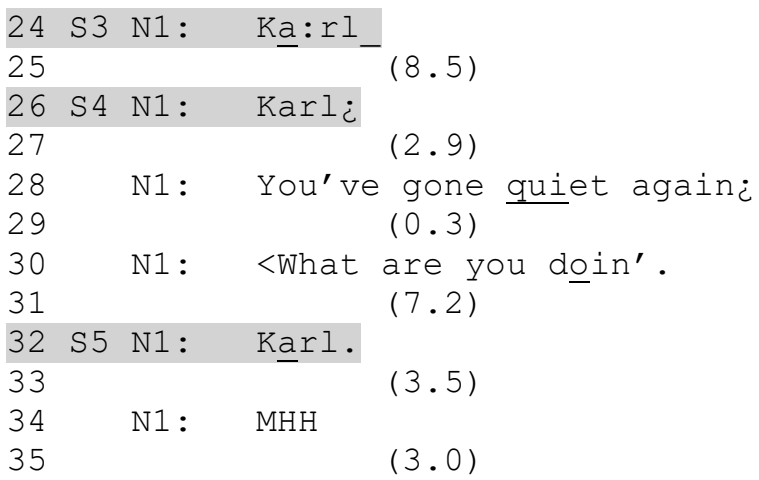

Following two more summonses in lines 24 and 26, N1 orients to PiC's unwillingness to respond, with actions other than summoning. First, in line 28, N1's 'noticing' that "You've gone quiet again $\dot{c}$ ", with which N1 treats PIC's unresponsiveness as a matter of his own choice, more to do with his willingness than his ability to respond. N1 again treats PiC's unresponsiveness as a choice with her information request in line 30 ("What are you doin'."), suggesting PiC must be otherwise engaged, and thereby testing PiC's reason for not responding. $\mathrm{N} 1$ displays no admonishment or critical concern for the time being.

Phonetically, while the pitch maximum (about $290 \mathrm{~Hz}$ ) and overall loudness of these summonses (S3-5) are similar to S1-S2, they differ from S1-S2 and each other in terms of pitch range and contour, and articulation. S3 has a flat-falling pitch contour, S4 has a flatrising pitch contour, and S5 a falling pitch contour. S3 is approximately 0.1 seconds longer than S4 and S5: it is primarily the prolonged vowel which makes up for this difference in duration. S3's vowel quality is also more centralised and diphthongised than S4 and S5, whereas S5 has a slightly more centralised vowel quality than S4. The pitch, intensity and duration features of S3-S5 are illustrated in Figure 1 (middle two rows). 


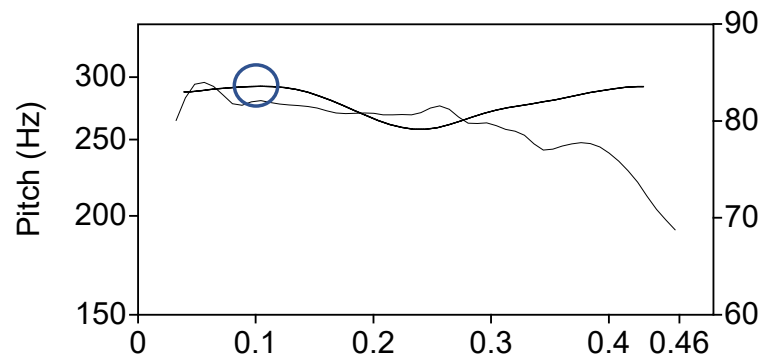

S3 (Extract 3, line 24): “Kạ:rl_"

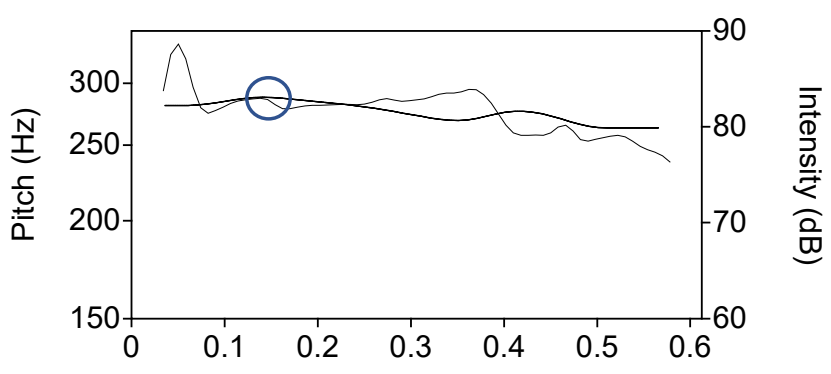

S5 (Extract 3, line 32): "Karl.”
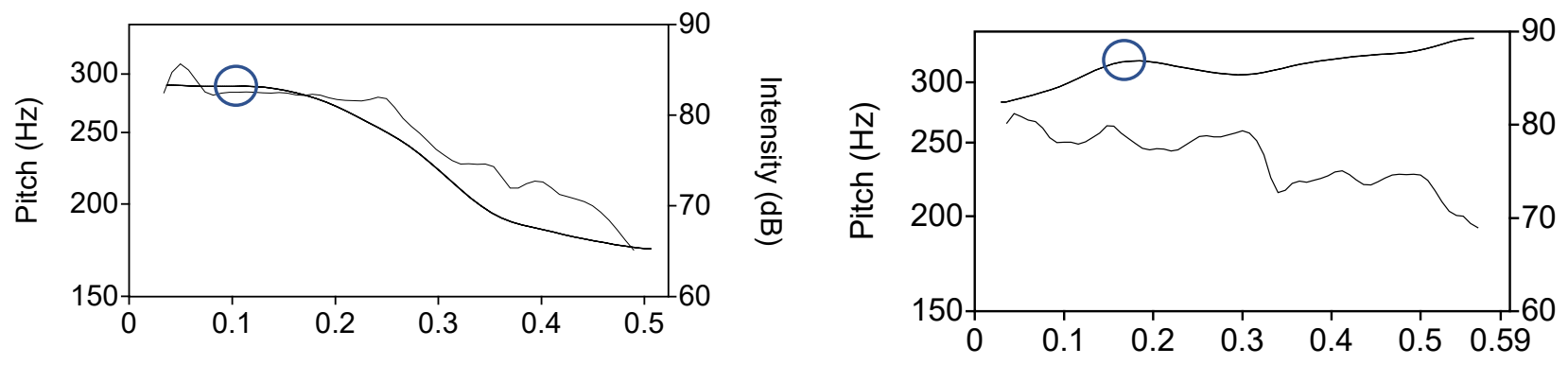

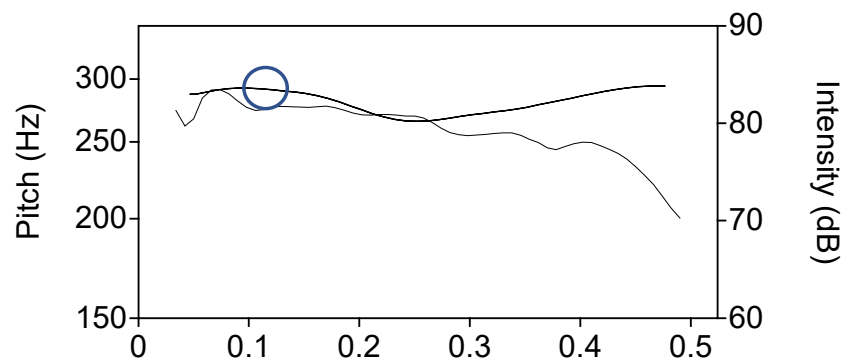

S4 (Extract 3, line 26): “Karlc"

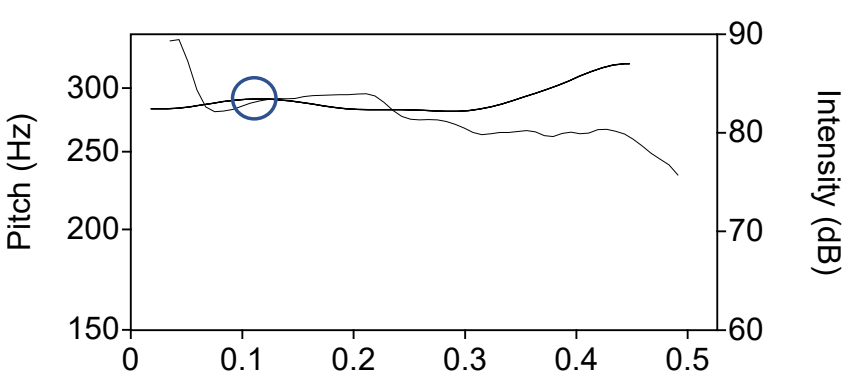

S6 (Extract 4, line 129): “Ka:rl,"

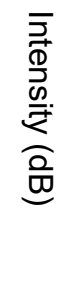

S7 (Extract 4, line 131): “个纤:rl.”

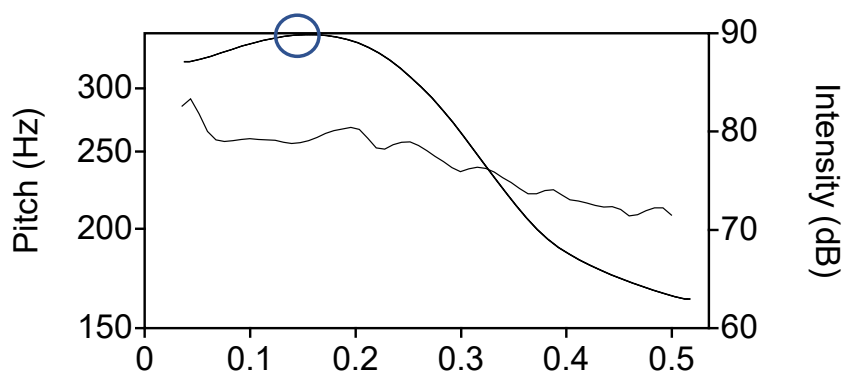

Figure 1. Pitch contour duration for summonses S1-S2 (Extract 2), S3-S5 (Extract 3) and S6-S7 (Extract 4). Pitch in $\mathrm{Hz}$ is shown with dotted lines and values on the left axis. Intensity is shown with solid lines and values on the right axis. Duration is shown on the bottom axis. Circle marks pitch accent maxima (Pierrehumbert, 1980). 
Extracts 2 and 3 illustrate how similar or slight phonetic upgrades in terms of pitch maxima, and small variations in loudness, duration and articulation, seem consistent with the categorisation 're-doings'. None of this phonetic variation is associated with an intensified effort to remedy unresponsiveness. N1 indicates some frustration following this series of summons, with a loud nasal outbreath in line 34: while this may be associated with a change in stance (frustration), it is seemingly not designed to be heard by PiC (although it might be hearable by the other negotiators) and is not displaying an orientation to increased urgency or concern. Extracts 4-6, on the other hand, represent cases where there is such evident change in urgency and concern. We will see that it is particularly increased pitch maximum, overall loudness and tighter/more peripheral articulations which is associated with these 'escalations'.

Extract 4 continues the case with Karl as PiC (see Extracts 2 and 3), where another two and a half minutes have passed with no response from PiC. The negotiators have just established that $\mathrm{PiC}$ is still visibly on the roof. Prior to Extract 4, the negotiators are debating whether to progress closer to PiC's location, but they conclude that this is too risky.

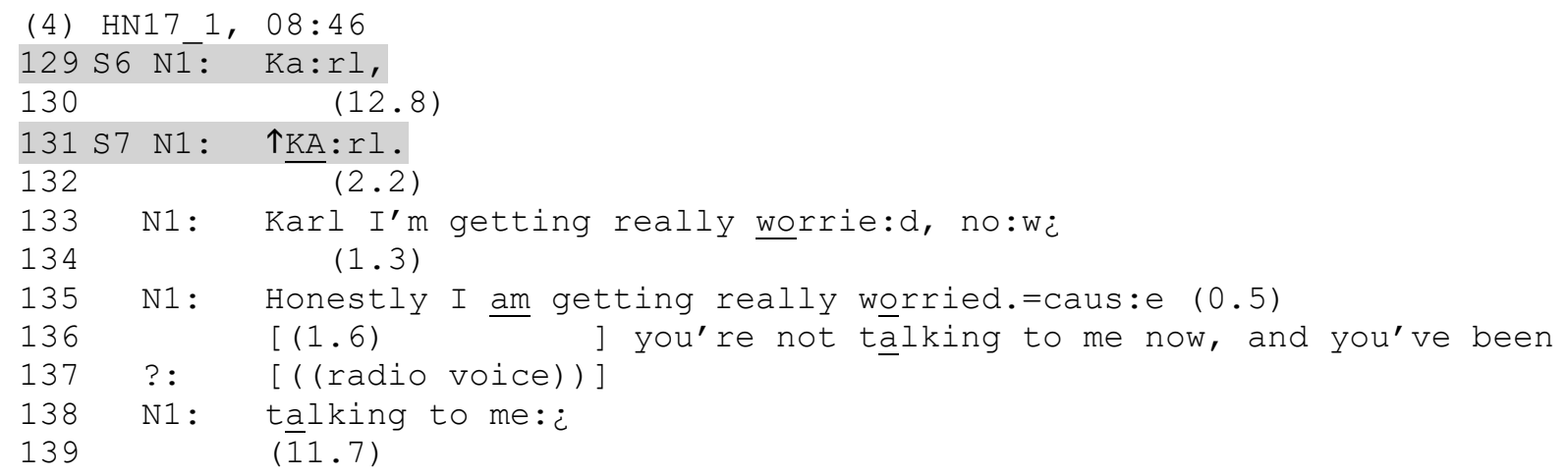

N1 treats her own summons in lines 129 and 131 as associated with added concern. First in line 133, "Karl I'm getting really worrie:d,", further enhanced in line 135, "Honestly I am getting really worried.". It is on this basis I argue that instead of treating her previous summons as a subsequent ('re-doing') attempt at securing PiC's response, N1 now shows that she 'escalates' her summoning. Phonetically, this 'escalation' involves greater phonetic upgrade than found for 're-doings' (see Figure 1, bottom row).

S7 shows a marked increase in pitch maximum, compared to S6. S7 is phonetically upgraded in terms of having a pitch maximum of $350 \mathrm{~Hz}$, compared to $320 \mathrm{~Hz}$ in $\mathrm{S} 6$ (a difference of 2 semitone). Further, S7 is noticeably louder than S6 (the intensity visualised in Figure 1 contributes to this perception; see Section 2). And compared to S6, the vowel in S7 is monophthongal and peripheral in its vowel quality, and 0.1 seconds shorter. The prevocalic consonant is also markedly tighter in S7 compared to S6.

While I primarily compare $\mathrm{S} 7$ to $\mathrm{S6}$, the phonetic upgrades are also worth comparing with reference to earlier summonses (Extract 2-3): following an extended series of summons sequences, it is the first time N1 significantly exceeds both the pitch maxima of S1-S5. Both S6 and S7 show an upward shift in pitch maximum compared to S1-S5; however, S7 shows 
the most marked difference, particularly in terms of pitch maximum (a difference of $60 \mathrm{~Hz}$ or 3 semitones). $\mathrm{S} 7$ also has a much wider pitch range than the preceding summonses, with a much sharper rise-fall contour compared to S5. In context of N1's own demonstrable orientations to growing concern here, $\mathrm{S} 6$ and S7's gradual increase in pitch maximum, and $S 7$ 's increased pitch range and tighter/more peripheral articulation seem to provide resources for $\mathrm{N} 1$ to 'escalate' the summoning.

In further evidence of a relative increase in phonetic upgrading of, in particular pitch maximum, loudness and articulatory setting, we turn to a different crisis negotiation, in which negotiators use summonses to maintain the attention of a PiC whose situation is getting increasingly critical (Extracts 5 and 6). PiC, here anonymised as Jessica, is barricaded inside her flat with a noose around her neck and holding a knife. In this case, PiC and N1 already have mutual and visual contact as $\mathrm{N} 1$ can see PiC through a gated but locked door into her flat. N1's main project is to get PiC to hand him the keys through the gate. In the last couple of minutes prior to Extract 6, PiC has tightened the noose around her neck, and $\mathrm{N} 1$ has suggested she undo/loosen it. $\mathrm{PiC}$ sounds as if she has trouble breathing (transcribed using $\left.a^{(* \prime}\right)$. In response to growing concern and urgency, the negotiator increasingly escalates the summoning.

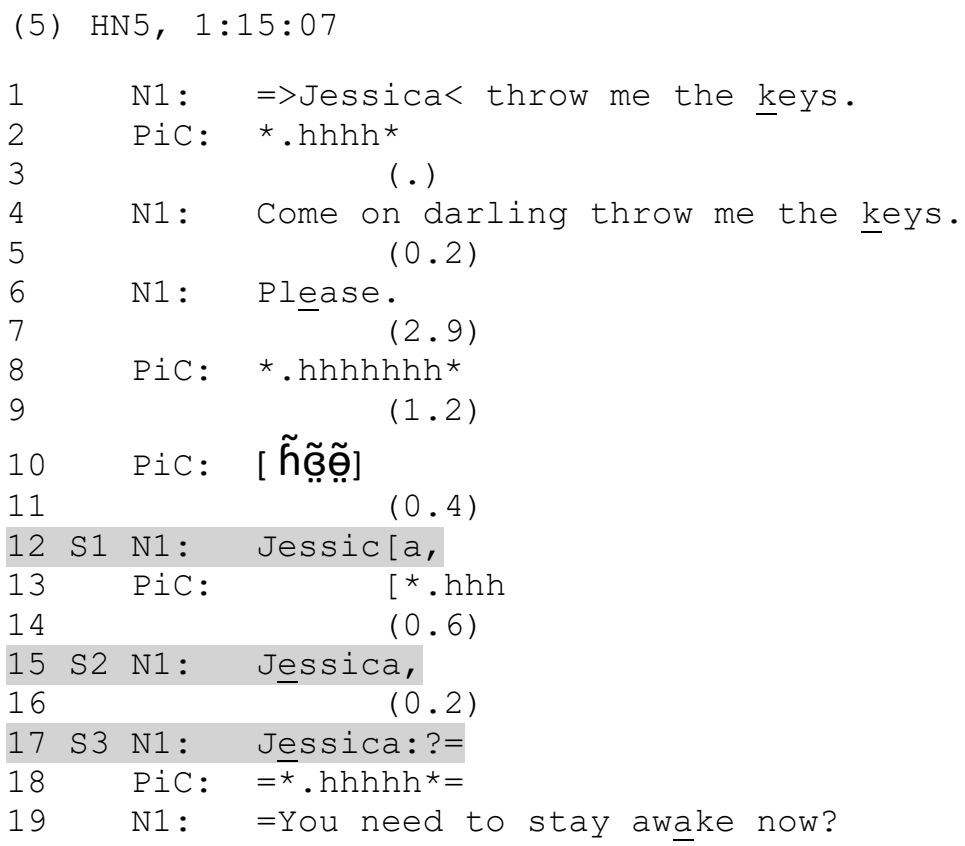

N1 has moved from requesting the keys to an imperatively formed directive in line 1: "throw me the keys.", which he repeats in line 4 . In lines 2 and 8 , PiC does not provide any lexical responses, but produces a series of strained inbreaths, which is also observed in lines 13 and 18 . Line 10 represents a potential lexical response to N1's request. It is produced on a breathy, nasalised voice which sounds much less strained that the surrounding breathing and does not hearably express for example physical efforts in managing the noose. Its

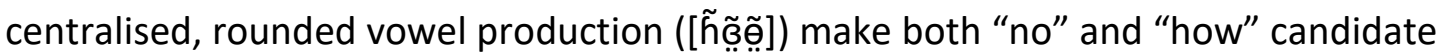
hearings, but this is highly ambiguous: N1 does not treat the vocalisation as a second pair 
part to his request, but seeks to secure joint attention to a current interactional focus with the summonses in lines 12, 15 and 17. While these summonses open for new opportunities for PiC to respond to N1's request, they seem to intensify N1's efforts and project a shift from pursuing a request to $\mathrm{N} 1$ displaying concern about PiC's basic abilities to stay engaged and breathing. This shift is evidenced through N1 urging PiC to stay awake ("you need to stay awake now?", line 19), indicating a critical, dangerous moment is emerging.

The increasing orientation to danger is associated with some phonetic upgrade in the subsequent summonses: S2 has a pitch maximum of about 2 semitones higher than S1 and a wider pitch range. S3 has a similar pitch maximum to S2 and ends on a higher, rising pitch. S2 and S3 are both also noticeably louder than S1 and have more peripheral vowel production. The pitch, intensity and duration features are presented in Figure 2.

There are shorter gaps between summonses, compared to the longer gaps in Extracts 2-4. One explanation for this difference could be that N1's concern in Extracts 5-6 is not associated with a maintained silence and non-participation (Extracts 2-4), but in orientation to PiC's unfolding attempt to do harm to herself.

While N1 seems to gradually escalate the seriousness of the situation in Extract 5, a significantly more marked contrast occurs approximately 4 minutes later in this encounter. This case gives further support to the claim that participants do indeed monitor the level of phonetic upgrading in self-repeated summons: in this case a self-repeated summons warrants an intervention from the second negotiator, to "keep calm". This excerpt also involves PiC's dog (D), who the negotiators have brought into the scene from the outside.

(6) HN5, $1: 19: 53$

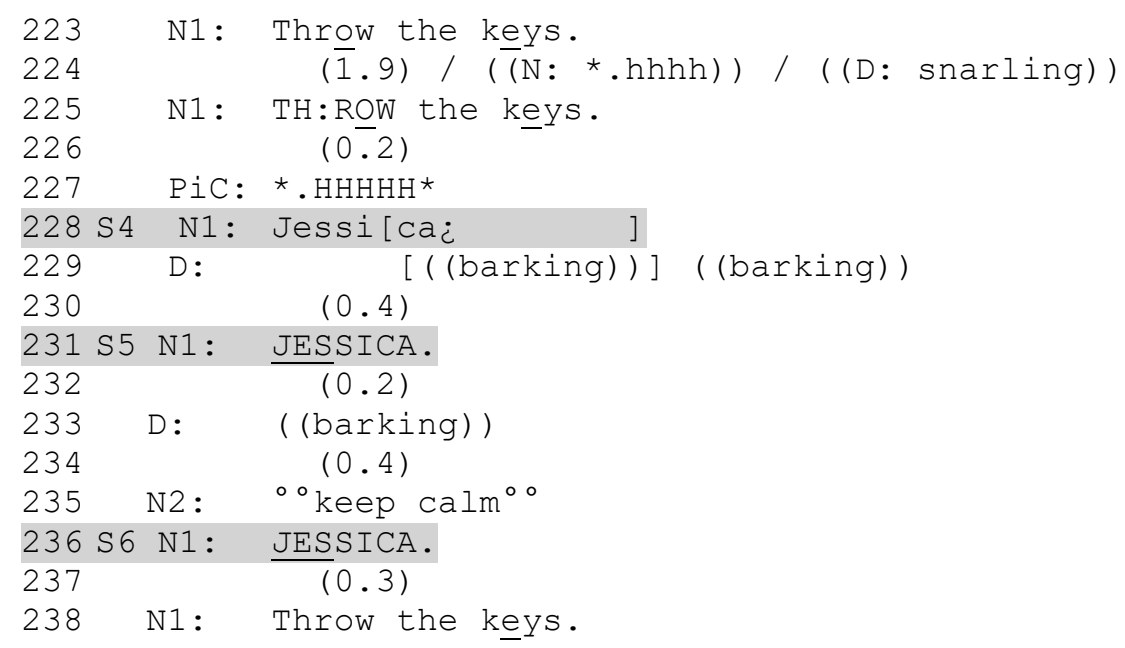




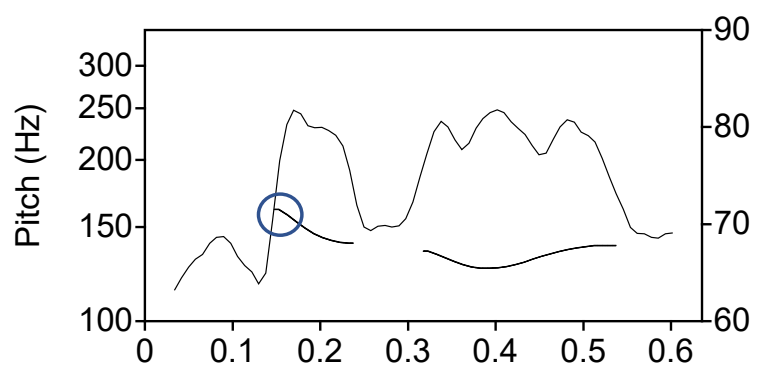

S3 (Extract 5, line 17): "Jessica:?"

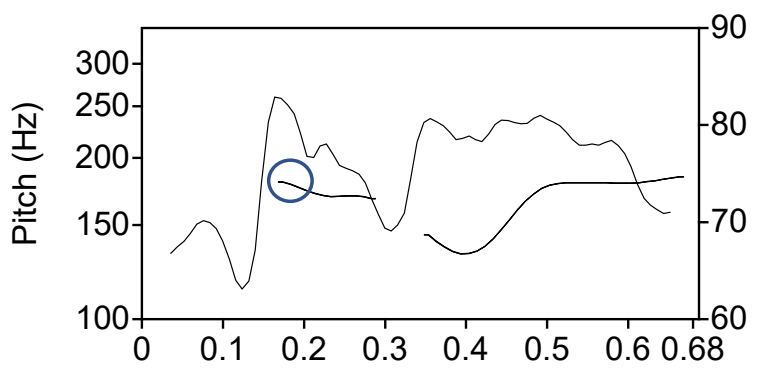

S5 (Extract 6, line 231): "JESSICA."

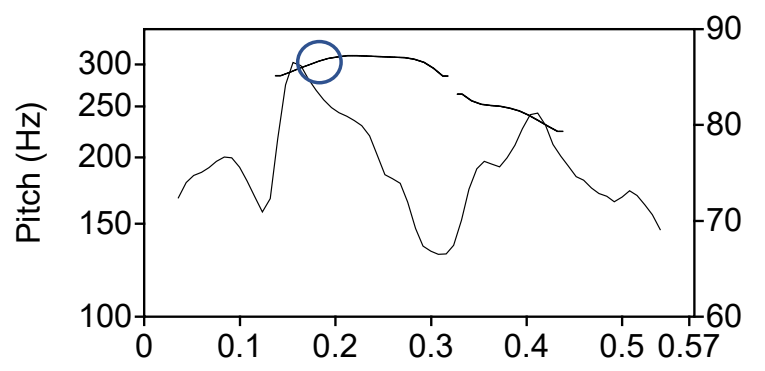

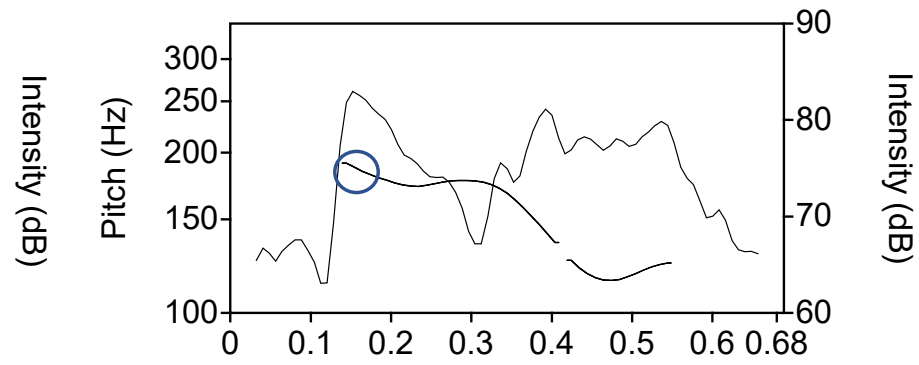

S4 (Extract 6, line 228): “Jessicą"

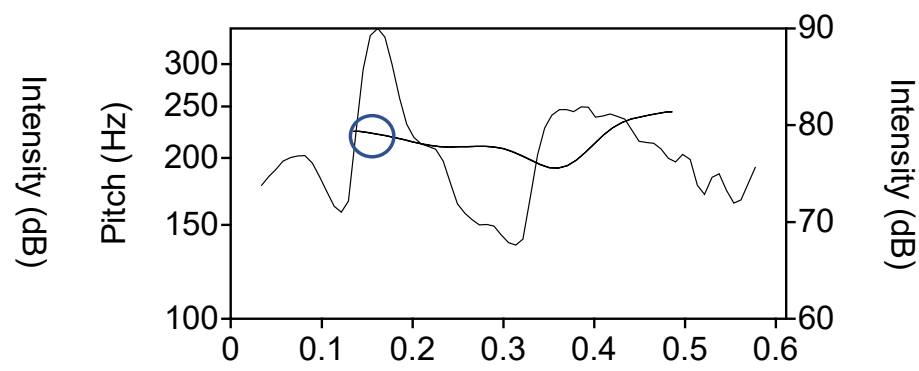

S6 (Extract 6, line 236): "JESSICA."

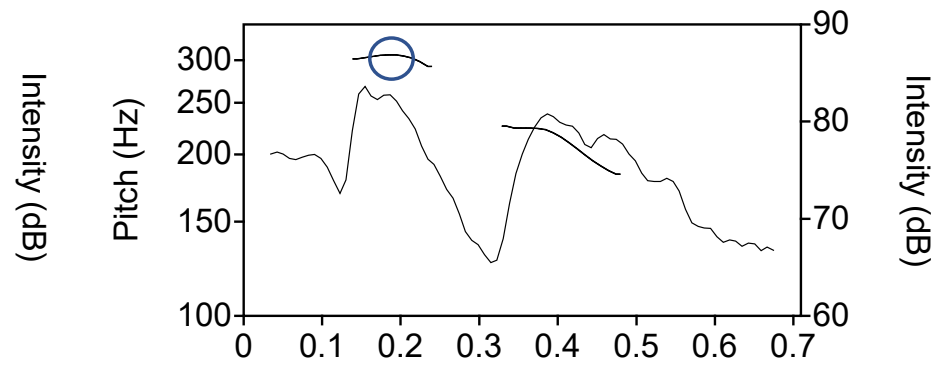

Figure 2. Pitch contour duration for summonses S1-S3 (Extract 5), and S4-S6 (Extract 6). Pitch in $\mathrm{Hz}$ is shown with dotted lines and values on the left axis. Intensity is shown with solid lines and values on the right axis. Duration is shown on the bottom axis. Circle marks pitch accent maxima (Pierrehumbert, 1980).

While N1 has persisted with the directive 'throw the keys' (lines 223 and 225: noticeably louder in the latter production), $\mathrm{PiC}$ 's trouble of breathing has only got worse (line 227). N1 repeats his summons in line 231, this time with a significantly louder and higher pitch maximum (S5 in Figure 4). The pitch maximum is 7 semitones higher in S5 compared to S4, and N1 has changed from a final rise to a falling pitch contour. S5 also has much tighter articulation of the prevocalic consonant and the pitch accent vowel is more peripheral than the previous summonses. The intensity peak drops in S5 compared to S4, however the loudness (influenced also by perceived vocal effort) is noticeably highest in S5.

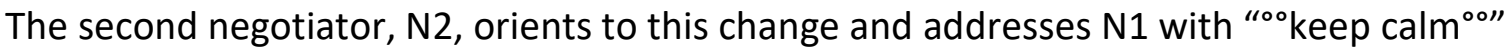


(line 235). In other words, the phonetic contrast is not just measurable as larger than normal, it is also treated as such by the co-participants. The final summons, S6, shows similar pitch and articulation features to S5, but noticeably quieter: N1 does not escalate the summoning any further.

In summary, this section has shown how negotiators maintain ('re-doing') the summoning or escalate it beyond mere persistence, and by doing so they change the nature of the summoning activity, i.e., 'escalating' the seriousness and critical nature of the situation. The phonetic design of 'escalations' differ from 're-doings' in that they have more marked phonetic upgrades in pitch maxima and range (with sharp falling contour), loudness, and tighter/more peripheral articulations. The small variability in duration is less clearly associated with distinguishing 're-doings' from 'escalations'. Crucially, the phonetic design of summonses is treated by the negotiators themselves as relevant in displaying concern, or responsiveness to an emerging crisis.

\section{2 'Summoning' the verbally engaged: Phonetic upgrading and downgrading to an interactional shift}

Section 3.1 showed that speakers may choose to persist summoning in a non-escalatory ('re-doing') or 'escalatory' manner, and how phonetic variation makes this distinction possible. In this section, I present one example (Extract 7) that differs from the above in that the recipient is already verbally engaged and out of danger, and the summoning seems to mark and mobilise some shift in PiC's attention. The repeated summoning becomes relevant to re-focus the conversation and the recipient onto a new course of action, and the negotiator seems to phonetically downgrade their repeated summons to do so. I argue that this could be a case of summons 'attenuation' (Hauser, this issue).

In Extract 7 the negotiator is currently talking to PiC over the phone, situated on the street outside PiC's flat. $\mathrm{N}$ attempts to negotiate a meeting face-to-face with PiC. While PiC is verbally engaged, he expresses substantial emotional distress to do with his suicidal history, past medicine use and hospitalisation.

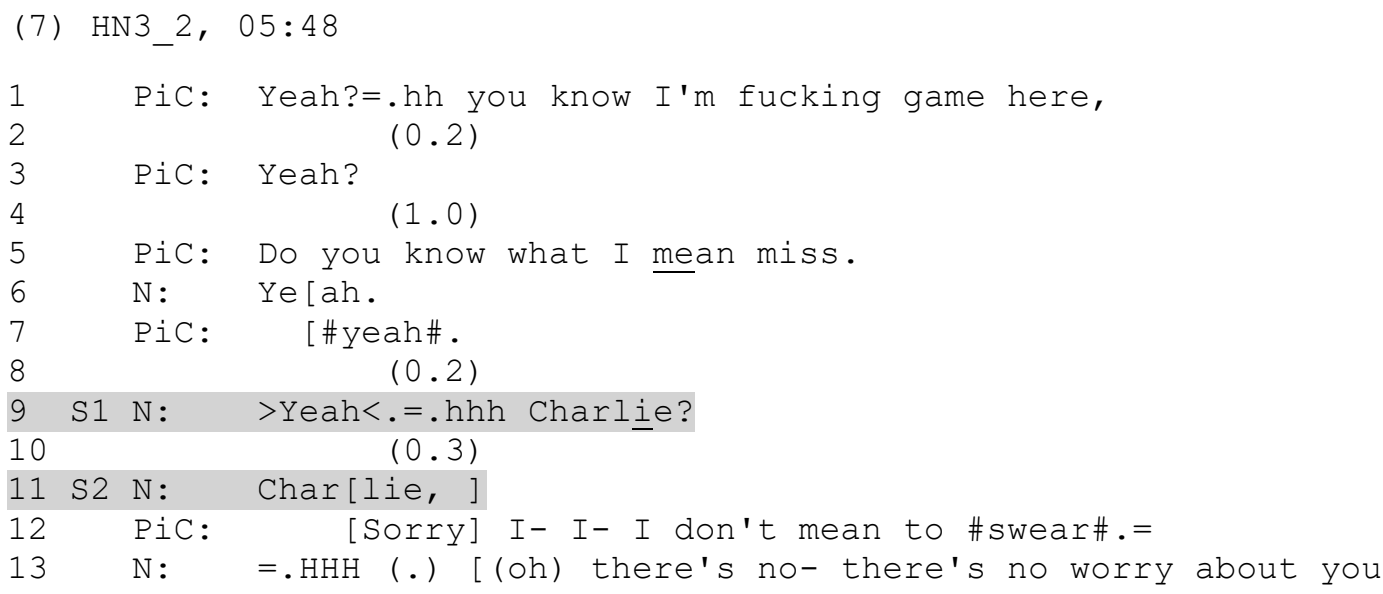




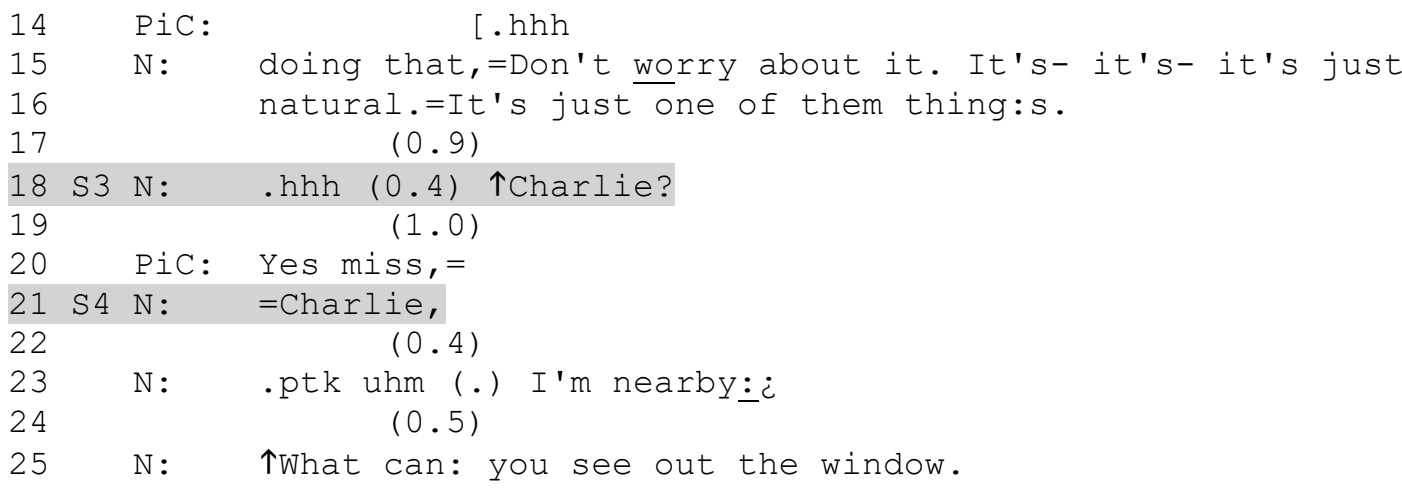

In line 1 PiC concludes that "I'm fucking game here,", following extended talk about how he has given up on life despite his own and others' efforts to change his life situation. However, in this case it is $\mathrm{N}$ who remains unresponsive: $\mathrm{PiC}$ pursues a response with "Yeah?" (line 3) and "do you know what I mean miss." (line 5), and $\mathrm{N}$ confirms in line 6, before seemingly initiating a shift in agenda in line 9 (see Clayman, 2013; Butler et al., 2011). The new topic is initiated with a summons, which $\mathrm{N}$ repeats in line 11 , in overlap with $\mathrm{PiC}^{\prime} \mathrm{s}$ apologies for using a swear-word ('fucking', from line 1). $N$ denies that swearing would have any consequence for her engagement with $\mathrm{PiC}$ in lines 13-16, and then re-initiates the sequence shift in line 18, this time followed by the go-ahead "Yes miss,". In both pairs of pre-sequences, lines 9 and 11 (S1 and S2), and in lines 18/21 (S3 and S4), the repetitions (S2 and S4) are phonetically downgraded compared to S1 and S3 respectively. In S2, the second summons is noticeably quieter than $\mathrm{S} 1$, and has a 3 semitones lower pitch maximum. S2 also has a more centralised vowel production compared to S1. A similar relationship is found when comparing S3 and S4; however, S3 has a higher onset pitch than S1, perhaps as a more marked attempt of a 'new beginning' (Couper-Kuhlen, 2004).

In this case, $\mathrm{N}$ is dealing with someone who is already verbally responsive, but seeking to re-orient the recipient's attention onto other, sequentially disjunct, matters. According to Clayman (2013), such use of address terms is used "for initiations directed to recipients who are engaged but pursuing a course of action at odds with what the speaker is about to launch" (p. 292). By repeating the use of address terms however, its producer might treat the recipient as available, able and willing to respond (and not as in danger or causing concern), but not (yet) displaying the appropriate attention or alignment. Although we are now dealing with address terms possibly outside the definition of a 'summons' (see Section 2), I propose a third category for such cases - 'attenuated' summons - in which securing the recipient's joint attention requires more work, but recipiency is basically in progress.

\section{Discussion}

This paper has explored how crisis negotiators use summonses to (re-)establish joint participation with a person in crisis, who may remain unavailable, unable or unwilling to 
respond. Through conversation analysis of self-repeated summonses, I have shown how summons-producers may subsequently 're-do' or 'escalate' their effort to get a response, displaying varying orientations to increased danger or concern; or 'attenuate' their effort and thereby treating the recipient as responsive but not yet attentive and/or aligned with a course of action.

In the remainder of this paper I discuss some of the wider implications of the findings, first on the relevance of 'upgrading' and 'downgrading', or 'regrading', in interaction, and secondly on the relevance of these findings for negotiators in their attempts respond to and deal with critical situations. I end this paper with some thoughts on limitations of this study and future directions.

One key point I would like to make is that phonetic analyses help us better understand how 'regrading' is relevant in designing recognisable social actions (CouperKuhlen, 2011; Ogden, 2012). This study also suggests that such 'regrading' may go beyond binary distinctions ('upgrading' and 'downgrading'), with a continuous range of phonetic features, involving pitch, loudness, articulation and duration, in this case linked to maintaining or escalating orientations to unresponsiveness. A slight phonetic upgrade of self-repeated summonses seems to avoid abandoning the current activity of summoning someone. This does not mean, however, that any phonetic 'upgrading' or 'downgrading' is to be treated as something markedly and interactionally different from what happened before. Instead, as I have shown, a slight phonetic upgrade in pitch and loudness can also be seen to persist in a 're-doing' that was initiated before but failed, a category which includes some phonetic variation (i.e., less categorizable as 'upgrading' or 'downgrading') in pitch contour, articulatory setting and duration as well. The critical point, however, is that most phonetic variation in the data do not exceed participants' expectations for what 're-doing' a summons should sound like; when they do, the summons-repeats are treated as altering the summoner's stance towards the unresponsiveness, for example by displaying increased orientations to danger or concern.

Some cases, for example in the case of Jessica (Extract 5), showed intensification in a less distinct, more gradual manner: in this case, the negotiator seemed to move towards treating the unresponsiveness as critical, by warning against imminent risk rather than responding to it as already happening. In these cases, the phonetic upgrading was not as clear-cut as in other 'escalations'. On such a basis one might argue against categorisation of 're-doing' and 'escalation', and instead argue for a more scalar approach to 'regrading' (in this case) self-repetitions. In this way, one might also seek to further account for the more fine-grained 'regradings' associated with (non-)escalation for example. But in either case, self-repetition is evidently not designed as just repeating, but managing and shaping interactional circumstances. That is, generally speaking, a self-repeated summons is treated as a subsequent (second, third, fourth, etc.) attempt at securing a response from the recipient, not assuming the first was irrelevant but shaping the subsequent summonses accordingly. 
A problem with applying an 'upgrading-downgrading' continuum (a two-dimensional scale), is that it does not necessarily cover all the relevant parts of a responsive action, in this case in seeking to remedy unresponsiveness. For example, variation between rising and falling contour summonses might be accounted for not in terms of upgrading-downgrading, but possibly for designing a summons as prospectively or retrospectively oriented, or as a final one in a series of summonses; these are potentially relevant distinctions not examined in this paper. And, although phonetic downgrading appeared interactionally distinctive from phonetic upgrading, this distinction did not simply map onto the level of crisis or concern, e.g. from 'escalation' to 'de-escalation'. The case of 'attenuated' summons repetition, for example, does not easily fit with the level of displayed danger or concern, but instead orients to the recipient's current focus of attentiveness. However, the two types of orientations, danger/concern and attentiveness, might both be relevant simultaneously: in a related study focussing on parent-child interactions, Kidwell (2013) notes in one case that a (phonetically) weaker second summons is associated less with preventing danger and more about sanctioning behaviour that has already ended, thereby treating both the danger as over while pursuing the recipient's attention. In other words, particular phonetic features associated with 'upgrading' and 'downgrading', even in relatively limited formats such as address terms, are not exclusive to just one interactional function (see Walker, 2014). But by focussing primarily on orientations to increased danger and concern, this paper offers some support for the interactional relevance of phonetic 'grading': future research in this area should remain focussed on what distinctions between fine-level phonetic (or lexical, gestural) 'regrading' emerge as relevant to interactional members.

This study contributes to conversation analytic research on the range of sequential environments in which address terms are used (see Butler et al., 2011). I have also added to the small number of studies exploring failed summons in different contexts, so far including conversations with many people, such as in classrooms (see Gardner, 2015), dealing with noncompliance in parent-child interactions (Kidwell, 2013), and dealing with unresponsiveness from psychiatric patients (Bergmann, 2016). The present paper shows how phonetic design features are used systematically to manage unresponsiveness and its potential consequences.

This is one of very few studies to explore crisis negotiations as they unfold in real time. While crisis negotiators are highly and increasingly well trained (Morabito et al., 2012), and it is known that these encounters are characterised by a high level of resistance (Vecchi 2009), there is little attention to the kind of detail provided by conversation analytic research, for example on how risk escalations are dealt with, and/or avoided. This study shows how negotiators escalate talk to deal with, and distinguish, critical and non-critical situations, by exploring more 'passive' forms of resistance from the person in crisis, treated by the negotiator as signs of (more or less critical) unresponsiveness. A negotiator may repeat the summoning to markedly and accountably escalate the interactional circumstance in which they seek attention from the person in crisis. 
Initially I noted what a powerful resource summoning can be (see Kidwell, 2013); but one may question the effectiveness of summonses based on this study. In most cases in the data, the person in crisis will respond following a summons, demonstrating the summons' power in seeking a recipient's joint participation. But in some cases, which I focus on here, the summoning was unsuccessful in that the person in crisis would remain silent, with no immediate change in behaviour following 'escalation' for example. The challenge, for the negotiator, is how to best deal with unresponsiveness. While the summoning appears unsuccessful in these cases, the negotiators also have to consider the risks associated with moving closer to the person in crisis (climbing up on the roof or breaking in to the flat); it might also be particularly risky to summon a person in crisis who is situated on the edge of a roof. Still, in the case of Jessica (Extracts 5 and 6), following the negotiator's maintained and escalated summoning and directives, she eventually throws the keys. While there is no evidence that the 'escalation' does something to speed up this process, one might argue that it is through continued presence and displayed persistence that the negotiators end up saving PiC's life.

Finally, a weakness of this study is that there is no available video-data, in which one might identify other cues, for example negotiators moving closer to a person in crisis or interacting non-verbally with their colleagues. This is a project for the future, which could give further insights into how summoning, along with other actions, are best used in dealing with continued unresponsiveness.

\section{Conclusion}

Doing less, more and markedly more than previous talk is something that phonetic design is well suited to distinguish. In this paper, phonetic 'regrades' of self-repeated summoning is treated as interactionally relevant to timely and appropriately deal with an emerging crisis. This study provides evidence of how, based on phonetic features, some 'repetitions' escalate a situation, while others merely persist in (re-)doing what has so far failed.

\section{References}

Allen, George D., 1971. Acoustic level and vocal effort as cues for the loudness of speech. The Journal of the Acoustical Society of America 49(6B), 1831-1841.

Bergmann, Joerg, 2016. Making Mental Disorders Visible: Proto-Morality as Diagnostic Resource in Psychiatric Exploration. The Palgrave Handbook of Adult Mental Health. Springer.

Boersma, Paul, \& Weenink, David, 2018. Praat: doing phonetics by computer. Version 6.0. 37.

Bolden, Galina B., Mandelbaum, Jenny, Wilkinson, Sue, 2012. Pursuing a Response by Repairing an Indexical Reference. Research on Language \& Social Interaction, 45(2), 137-155.

Butler, Carly W., Danby, Susan, \& Emmison, Michael, 2011. Address terms in turn beginnings: managing disalignment and disaffiliation in telephone counseling. Research on Language \& Social Interaction, 44(4), 338-358.

Cekaite, Asta, 2009. Soliciting teacher attention in an L2 classroom: Affect displays, classroom artefacts, and embodied action. Applied Linguistics, 30(1), 26-48. 
Clayman, Stephen E., 2013. Agency in response: The role of prefatory address terms. Journal of Pragmatics, 57, 290-302.

Couper-Kuhlen, Elizabeth, 2004. Prosody and sequence organization in English conversation: The case of new beginnings. In Couper-Kuhlen, E. and Ford, C. E. (Eds.), Sound patterns in interaction: Cross-linguistic studies from conversation, pp. 335-376. Philadelphia: Benjamins.

Couper-Kuhlen, Elizabeth, 2011. Pragmatics and prosody: Prosody as social action. Foundations of Pragmatics, 491-510. Berlin: Mouton de Gruyter.

Curl, Traci, 2002. The phonetics of sequence organization: an investigation of lexical repetition in otherinitiated repair sequences in American English. Doctoral dissertation, University of Colorado.

Curl, Traci, 2005. Practices in Other-Initiated Repair Resolution: The Phonetic Differentiation of "Repetitions." Discourse Processes, 39(1), 1-43.

Curl, Traci, Local, John, Walker, Gareth, 2006. Repetition and the prosody - pragmatics interface. Journal of Pragmatics, 38, 1721-1751.

Davidson, Judy, 1984. Subsequent versions of invitations, offers, requests, and proposals dealing with potential or actual rejection. In Atkinson, J. Maxwell, and Heritage, John (Eds.), Structures of social ction: Studies in conversation analysis, pp. 102-128. Cambridge University Press.

Gardner, Rod, 2015. Summons turns: The business of securing a turn in busy classrooms. In International perspectives on classroom interaction.

Good, Jeffrey S., Beach, Wayne, 2005. Opening up gift-openings: Birthday parties as situated activity systems. Text - Interdisciplinary Journal for the Study of Discourse, 25(5), 565-593.

Heritage, John, Raymond, Geoffrey, 2005. The Terms of Agreement: Indexing Epistemic Authority and Subordination in Talk-in-Interaction. Social Psychology Quarterly, 68(1), 15-38.

Jefferson, Gail, 2004. Glossary of transcript symbols with an introduction. Pragmatics and Beyond New Series, 125, 13-34.

Kidwell, Mardi, 2013. Availability as a trouble source in directive-response sequences. In Hayashi, Makoto, Raymond, Geoffrey, Sidnell, Jack (Eds.), Conversational Repair and Human Understanding, pp. 234-383. Cambridge University Press.

Lerner, Gene, 2003. Selecting next speaker: The context-sensitive operation of a context-free organization. Language in Society, 32(2), 177-201.

Lester, David, Brockopp, Gene W., 1973. Crisis Intervention and Counseling by Telephone. Springfield, Illionois: Charles C Thomas.

Local, John, 1992. Continuing and restarting. In Auer, Peter, and Di Luzio, Aldo (Eds.), The Contextualization of Language. John Benjamins Publishing Company.

Local, John, 2003. Variable domains and variable relevance: interpreting phonetic exponents. Journal of Phonetics 31(3), 321-339.

Local, John, Auer, Peter, Drew, Paul, 2010. Retrieving, redoing and resuscitating turns in conversation. In Barth-Weingarten, Dagmar, Elisabeth Reber, and Margret Selting (Eds.), Prosody in Interaction, pp. 131159. John Benjamins Publishing.

Morabito, Melissa S., Kerr, Amy N., Watson, Amy C., Draine, Jeffrey, Ottati, Victor, Angell, Beth, 2012. Crisis Intervention Teams and People With Mental Illness: Exploring the Factors That Influence the Use of Force. Crime \& Delinquency, 58(1), 57-77.

Ogden, Richard, 2006. Phonetics and social action in agreements and disagreements. Journal of Pragmatics, 38(10), 1752-1775.

Ogden, Richard, 2012. Prosodies in conversation. In Niebuhr, Oliver (Ed.), Understanding prosody: The role of 
context, function and communication, pp. 201-208. Walter de Gruyter.

Pierrehumbert, Janet B., 1980. The phonology and phonetics of English intonation (Doctoral dissertation, Massachusetts Institute of Technology).

Plug, Leendert, 2014. On (or not on) the "upgrading-downgrading continuum": The case of "prosodic marking"in self-repair. In Barth-Weingarten, Dagmar, and Beatrice Szczepek Reed Prosodie Und Phonetik in Der Interaktion. Mannheim: Verlag für Gesprächsforschung.

Pomerantz, Anita, 1984a. Agreeing and disagreeing with assessments: Some features of preferred/dispreferred turn shaped. In Atkinson, J. Maxwell, and Heritage, John (Eds.), Structures of social action, pp. 57-101. Cambridge: Cambridge University Press.

Pomerantz, Anita, 1984b. Pursuing a response. In Atkinson, J. Maxwell, and Heritage, John (Eds.), Structures of social action, pp. 152-164. Cambridge: Cambridge University Press.

Sacks, Harvey, 1992. Lectures on conversation (Vols. 1 and 2). (G. Jefferson, Ed.). Oxford: Blackwell.

Schegloff, Emmanuel A., 1968. Sequencing in conversational openings. American Anthropologist, 70(6), 10751095.

Schegloff, Emmanuel A., 2004. On dispensability. Research on Language \& Social Interaction, 37(2), 95-149.

Sorjonen, Marja-Lena, Hakulinen, Auli, 2009. Alternative responses to assessments. In Sidnell, Jack (Ed.), Conversation Analysis, pp. 281-303.

Vecchi, Gregory, 2009. Conflict and crisis communication: A methodology for influencing and persuading behavioral change. Annals of the American Psychotherapy Association, Vol 12(1), 34-42.

Voilmy, Dimitry, Wiklund, Mari, 2013. Syntactic and Prosodic Forms of First Names in Institutional Interaction Involving Multiple Participants. Discours. Revue de Linguistique, Psycholinguistique et Informatique., 13.

Walker, Traci (2014). Form $\neq$ function: The independence of prosody and action. Research on Language and Social Interaction, 47(1), 1-16.

Walker, Gareth (2017). Visual Representations of Acoustic Data: A Survey and Suggestions. Research on Language and Social Interaction, 50(4), 363-387.

Walker, Gareth (2017). Young children's use of laughter as a means of responding to questions. Journal of Pragmatics, 112, 20-32. 